Cadernos de

Pesquisa do CDHIS

DOI 10.14393/cdhis.v33n2.2020.56818

\title{
A Cidade como um Arquivo Aberto para o Ensino de História
}

The City as an Open Archive for the Teaching of History

Cibele Aparecida Viana ${ }^{1}$

${ }^{1}$ Mestre em História pela UFOP- Programa de Pós Graduação em História- UFOP e doutoranda do Programa de Pós Graduação em História da UFOP, Brasil. Email: cibelouro@yahoo.com.br 


\section{RESUMO:}

Geralmente, ao pensarmos em arquivo, de imediato nos reportamos à história registrada em documentos (muitos dos quais "oficiais", chancelados pelas instituições), mas cabe ressaltar que o patrimônio histórico-cultural de uma cidade "guarda" por trás de papeis e edificações inúmeras vivências e memórias. O propósito deste trabalho é discutir as possibilidades de utilização dos arquivos para o ensino de História considerando tanto a literatura como a cidade como arquivos enunciadores de memórias individuais e coletivas de extrema importância para a sociedade, seja no âmbito local ou em mediações culturais que extrapolam suas fronteiras em diálogos transversais com a pluralidade de histórias de toda humanidade. Como um exemplo do recurso à literatura e à cidade para interpretação do patrimônio e das memórias no ensino de História, reconstituo um projeto pedagógico interdisciplinar que conduzi, junto com a professora de Literatura, com as turmas do ensino fundamental e médio da Escola Municipal de Águas Claras (distrito de Mariana-MG). Seu objetivo era interpretar o patrimônio e as memórias da cidade de Itabira, onde nasceu Carlos Drummond de Andrade, através de uma visita guiada à sede urbana desse município, com leitura de seus poemas que encontram-se dispostos em placas em diversas ruas da cidade, em uma iniciativa do Museu de Território "Caminhos Drummondianos".

Palavras-chave: Ensino de História; arquivos; literatura; cidade; patrimônio histórico, memórias.

\section{ABSTRACT}

Generally, when we think of archives, we immediately refer to the story recorded in documents (many of them are "official", certified by the institutions), however it is worth mentioning that the historical heritage of a city is more than papers and countless buildings, but it also brings experiences and memories. The purpose of this paper is to discuss about the possibilities of using archives for teaching History considering the literature, the city and also the enunciating archives of individual and collective memories, all of them are extremely important to the society. They can rise from the local level or in cultural mediations which go beyond their borders in transversal dialogues with the plurality of stories from all humanity. As an example of the use of the literature and the city for the interpretation of heritage and memories in the teaching of History, an interdisciplinary pedagogical project was conducted by me and the Literature teacher, applied to the students from elementary and high school classes of the school "Escola Municipal de Águas Claras" (district of Mariana-MG). Its objective was to interpret the heritage and the memories of the city of Itabira, where Carlos Drummond de Andrade was born, through a guided tour of the urban headquarters of that town, by reading his poems that are displayed on signs in several streets of the city, an initiative of the museum "Museu de Território Caminhos Drummondianos"

Keywords: Teaching of History; archive; literature; city; historical heritage, memories . 
A Cidade como um Arquivo Aberto para o Ensino de História

\section{1- O Ensino de História e as Fontes}

O conhecimento histórico, desde sua formulação como disciplina em meados do século XVIII, procura significar a multiplicidade do vivido por meio de uma gama muito variada de vestígios - escritos, orais, iconográficos, sonoros e materiais deixados pela ação humana no tempo. ${ }^{2} \mathrm{O}$ historiador francês Jacques Le Goff, integrante da Escola dos Annales, expôs a necessidade de perceber-se tais registros como um "produto da sociedade que o[s] fabricou segundo suas relações de forças que aí detinham poder". Dessa forma, tais documentos constituem-se, em dinâmica conjugada, também em monumentos, ou seja, em balizas simbólicas de legitimação de determinadas trajetórias e memórias sociais e apagamento de outras. (LE GOFF, 2003. p. 536).

Posteriormente, essa diversidade de vestígios também veio a ser empregada como fonte de interpretação no ensino de História. Tais práticas foram defendidas no Brasil desde a década de 1930, pela vertente conhecida como Escola Nova:

As novas tecnologias eram apontadas como recursos didáticos para o desenvolvimento dessa Escola Nova, como passou a ser denominado o conjunto de ideias que combatia o ensino tradicional. No Brasil, os defensores das propostas da Escola Nova sugeriam a utilização dos recursos audiovisuais, em especial do cinema (que havia tido um espetacular desenvolvimento nas décadas de 10 e 20), como uma maneira de estimular e tornar o processo de aprendizagem interessante para o educando. As Instruções Metodológicas elaboradas para auxiliar a aplicação dos programas de História para a escola secundária, impostos a todos os estabelecimentos escolares brasileiros, logo após a Reforma Francisco Campos (Decreto 19.890 de 1931), recomendavam a utilização da iconografia. Alegavam que os adolescentes tinham uma curiosidade natural pela imagem, e que por

2 Observe-se que até meados do século XX, o documento escrito, sobretudo oficial, obtinha primazia sobre os demais registros. 
este motivo os recursos tecnológicos deveriam ser utilizados no ensino secundário (ABUD, 2003, p. 186). ${ }^{3}$

Todavia, de forma geral, os registros históricos eram utilizados nas aulas e nos livros de História como ilustrações de um conteúdo previamente sistematizado e que deveria ser absorvido pelos alunos, ou ainda como uma "prova" acerca das narrativas didáticas que estavam sendo apresentadas aos discentes. $\mathrm{O}$ emprego desses registros, concebidos como um processo de transmissão direta de saberes construídos fora da escola, foi igualmente influenciado pela função ideológica e cultural do livro didático, como aponta Chopin:

É a função mais antiga. A partir do século XIX, com a constituição dos estados nacionais e com o desenvolvimento, nesse contexto, dos principais sistemas educativos, o livro didático se afirmou como um dos vetores essenciais da língua, da cultura e dos valores das classes dirigentes. Instrumento privilegiado de construção de identidade, geralmente ele é reconhecido, assim como a moeda e a bandeira, como um símbolo da soberania nacional e, nesse sentido, assume um importante papel político. Essa função, que tende a aculturar - e, em certos casos, a doutrinar - as jovens gerações, pode se exercer de maneira explícita, até mesmo sistemática e ostensiva, ou, ainda, de maneira dissimulada, sub-reptícia, implícita, mas não menos eficaz (CHOPIN, 2004, p.553)

Mais recentemente, sobretudo a partir da década de 1980, em um contexto de redemocratização política do país, o ensino de História, em interlocução com os debates do conhecimento histórico acadêmico, procedeu outros acionamentos das fontes históricas em sala de aula, buscando, através delas, problematizar os processos históricos, atentando para a pluralidade de versões e memórias nelas contidos ou silenciados. Tal prática foi inclusive incorporada por documentos oficiais formulados

\footnotetext{
3 Também o Manifesto dos Pioneiros, documento que sistematizou o pensamento dos defensores desta vertente educacional no Brasil, trouxe entre as diversas diretrizes educacionais propostas que "Os métodos e processos de ensino obedecerão às mais modernas conquistas das Ciências Sociais, da Psicologia e das técnicas pedagógicas.". (LEMME, 1997, p. 72).
} 
pelo Ministério da Educação, a exemplo dos Parâmetros Curriculares Nacionais, editados entre 1998 e 2000:

Ao longo do século XX, o documento adquire outra amplitude no trabalho do historiador. São utilizadas outras fontes de pesquisa histórica relacionadas à preocupação de se estudar outras dimensões da vida social. Os documentos passaram a ser tudo o que é registrado por escrito, por meio de sons, gestos, imagens ou que deixou indícios de modos de fazer, de viver e de pensar dos homens músicas, gravuras, mapas, gráficos, pinturas, esculturas, filmes, fotografias, lembranças, utensílios, ferramentas, festas, cerimônias, rituais, intervenções na paisagem, edificações etc. As fontes escritas passaram a ser variadas textos literários, poéticos e jornalísticos, anúncios, receitas médicas, diários, provérbios, registros paroquiais, processos criminais, processos inquisitoriais etc. (BRASIL, 1998, p. 84).

Abria-se, assim, um leque de opções para o tratamento do documento em sala de aula, no âmbito do ensino de História. No caso específico analisado neste artigo, dialogamos com a modalidade de prática pedagógica que o PCN de História do Ensino Fundamental define como "estudo do meio". Essa abordagem privilegia as saídas de sala de aula ou da escola, favorecendo a ampliação das percepções do aluno sobre um determinado objeto de estudo. ${ }^{4}$ Utilizar este tipo de metodologia requer uma preparação específica para não se transformar meramente em um passeio turístico:

O estudo do meio envolve uma metodologia de pesquisa e de organização de novos conhecimentos, que requer atividades anteriores à visita, levantamento de questões a serem investigadas, seleção de informações, observação de campo, confrontação entre os dados levantados e os conhecimentos já organizados por pesquisadores, interpretação, organização de dados e conclusões. Possibilita o reconhecimento da interdisciplinaridade e de que a apreensão do conhecimento histórico ocorre na relação que estabelece

\footnotetext{
${ }^{4}$ Por ocasião da realização do projeto, os PCNs eram uma das referências norteadoras do ensino de História, juntamente com a escolha do livro didático e as realidades das comunidades onde se localizavam os estabelecimentos escolares. A partir de dezembro de 2017, várias questões abordadas pelos PCNs foram alteradas pela BNCC.
} 
com outros conhecimentos físicos, biológicos, geográficos, artísticos. (BRASIL, 1998, p. 93).

É importante ressaltar que o estudo de meio realizado no âmbito dos perímetros urbanos não deve se ater somente à concepção de educação patrimonial, voltada para a sensibilização dos alunos quanto à preservação dos ícones físicos e culturais de uma cidade (SPINA; SERRATO, 2015, p. 101). Tal estudo precisa estar associado, em meu entender, à dimensão político-cultural dos processos, produções e expressões materiais ou imateriais indissociáveis das memórias e, em desdobramento, das identidades assumidas pelos grupos sociais que compõem tal espacialidade.

Cabe, portanto, aprofundar a compreensão da cidade como locus de manifestação de memórias, as quais, por sua vez, transformam-se no tempo, no interagir e conflituar das relações sociais:

De Babel a Brasília, como surgiu e se transformou a cidade? O próprio espaço urbano se encarrega de contar parte de sua história. A arquitetura, esta natureza fabricada, na perenidade de seus materiais tem esse dom de durar, permanecer, legar ao tempo os vestígios de sua existência. Por isso, além de continente das experiências humanas, a cidade é também um registro, uma escrita, materialização de sua própria história (ROLNIK, 1995, p. 9).

As cidades são expressões de memórias construídas e que se fixam ao longo do tempo. O acionamento dessas memórias envolve dimensões pessoais e comunitárias, que se interpenetram e alteram mutuamente (HALBWACHS, 2004, p.73). “Operação seletiva do passado mobilizada pelas condições de um tempo presente", como indica Maurício Aquino, a memória encontra-se continuamente “envolvida pela dinâmica da lembrança e do esquecimento mediada pela maleabilidade de diversos filtros sociais"; como a considerou Henry Rousso ${ }^{5}$, trata-se

\footnotetext{
${ }^{5}$ Maurício Aquino reporta-se ao seguinte texto: ROUSSO, Henry. A memória não é mais o que era. In: FERREIRA, Marieta de Moraes; AMADO, Janaína (orgs.). Usos \& Abusos da História Oral. Tradução de Luiz Alberto Monjardim et al. Rio de Janeiro: Editora da FGV, 1996, p. 94.
} 
de uma "reconstrução psíquica e intelectual que acarreta de fato uma representação seletiva do passado, um passado que nunca é aquele do indivíduo somente, mas do indivíduo inserido num contexto familiar, social, nacional". (AQUINO, 2015, p.253). Logo, as memórias interagem com elementos culturais e materiais que as traduzem de maneiras específicas, e permitem que sejam compartilhadas, alguns dos quais, considerados socialmente relevantes, até mesmo emblemáticos, são alçadas à condição de patrimônio histórico.

No caso das espacialidades tidas como tão significativas a ponto de serem consideradas (oficialmente ou não) como um patrimônio, entre as quais a própria ambiência urbana como um todo, o historiador Pierre Nora as denominou como "lugares de memória".

[...] os lugares de memória nascem e vivem do sentimento que não há memória espontânea, que é preciso criar arquivos, que é preciso manter aniversários, organizar celebrações, [...] se o que eles defendem não estivesse ameaçado, não se teria, tampouco, a necessidade de construí-los [...] (NORA, 1993, p.13).

Esses lugares de memória estimulam nossas recordações tanto pessoais quanto coletivas:

Existem lugares da memória, lugares particularmente ligados a uma lembrança, que pode ser uma lembrança pessoal, mas também pode não ter apoio no tempo cronológico. Pode ser, por exemplo, um lugar de férias na infância, que permaneceu muito forte na memória da pessoa, muito marcante, independentemente da data real em que a vivência se deu. Na memória mais pública, nos aspectos mais públicos da pessoa, pode haver lugares de apoio da memória, que são os lugares de comemoração. Os monumentos aos mortos, por exemplo, podem servir de base a uma relembrança de um período que a pessoa viveu por ela mesma, ou de um período vivido por tabela (POLLACK, 1992, p. 2-3).

Em suma, a cidade é um dos espaços "por excelência para a construção destes significados [memórias], expressos em bens culturais" (PESAVENTO, 1995, p. 281). 
De forma concomitante, o espaço urbano apresenta-se como uma espacialidade privilegiada para narrativas literárias acerca das vivências cotidianas e suas impressões na memória, como, por exemplo, procedeu Carlos Drummond de Andrade. Esse mosaico assim recomposto pelo diálogo entre Literatura e a História nos permite vislumbrar diversos aspectos da vida, na imbricação do subjetivo, do biográfico e do comunitário:

A representação da cidade na literatura depende do modo como o escritor faz do espaço urbano 'um objeto que precisa ser decifrado, uma escritura que precisa ser lida' $[\ldots]^{6}$. Aquilo que está sobre o texto-cidade: a cartografia urbana desnuda aspectos históricos e culturais, bem como, o cotidiano de vivências particulares e sociais por entre espaços, cujos rastos permanecem latentes dando ciência da relação que o homem estabelece com e na cidade. (SANTOS, 2013, p.66).

Experienciar a cidade em seus diversos aspectos, na sua efervescência do dia a dia, seus contornos naturais ou artificialmente criados pelo ser humano, sua diversidade arquitetônica etc., desencadeia narrativas mnemônicas. O modo como cada pessoa interpreta as experiências de um lugar é o que produz significado ao espaço físico. Com o passar do tempo, um conjunto de significados e experiências dão origem à memória social e tornam-se memórias intersubjetivas, na pluralidade dos grupos, gêneros, escolhas de vida etc. (LE GOFF,2003, p.181.)

A cidade sensível é aquela responsável pela atribuição de sentidos e significados ao espaço e ao tempo que se realizam na e por causa da cidade. Por esse processo mental de abordagem que o espaço se transforma em lugar, ou seja, portador de um significado e de uma memória; que passamos a considerar uma cidade como metrópole, realidade urbana que, desde o seu surgimento, causou uma revolução na vida, no tempo e no espaço; que criamos as categorias de cidadão e de excluído para expressar as diferenças visíveis e perceptíveis no contexto urbano fazendo com que se criem novas identidades a partir

\footnotetext{
6 - A autora transcreve o texto de autoria de Lucrecia D'Alésio Ferrara, intitulado Ver a cidade. São Paulo: Nobel, 1988, p.41.
} 
do gesto, do olhar e da palavra que qualifica; que falamos de progresso ou de atraso, que distinguimos o velho do antigo; que construímos a noção de patrimônio e instauramos ações de preservação, ou, em nome do moderno, que redesenhamos uma cidade, destruindo para renovar. São ainda os processos mentais de representação da realidade que nos permitem inventar o passado e construir o futuro, estabelecer as distinções entre rural e urbano, classificar ideias e práticas como modernas ou arcaicas, e considerar certas cidades como turísticas, rentáveis, sustentáveis. (PESAVENTO, 2007, p. 14-15. Itálicos da autora).

Pertencer a uma cidade implicou formas, sempre renovadas ao longo do tempo, de representar essa cidade, buscando diversas maneiras de conferir-lhe sentido, tanto em suas belezas quanto nas mazelas que a mesma possui. Através dos poemas Carlos Drummond, podemos vislumbrar a relação entre uma cidade "real" e imaginada:

Na cidade, constrói-se uma rede infinita de relações e repre-sentações [...] O estudo da cidade imaginada [por exemplo, pela literatura] é importante porque permite ampliar nossa compreensão do fenômeno urbano a partir da narrativa da memória. Ao rememorar, o narrador [ou o poeta, ou ainda os leitores desse poeta] revê[m] não as coisas em si, mas significados das coisas. Ele[s] se revisita[m]. Às imagens que vêm à tona corresponde um olhar a percorrer ruas, becos, calçadas, pessoas, brigas, amores, família, patrão, trabalho... A cidade é um livro-texto que se deixa desnudar pelo narrador. Este, ao mesmo tempo que olha, conta-lhe segredos, repete discursos (NOGUEIRA, 1998).

\section{2- A cidade interpretada através de poemas}

A discussão sobre a cidade como um local que carrega múltiplas memórias e que pode ser um suporte à interpretação e à partilha das sensibilidades nas aulas de História foi promovida em um projeto pedagógico do qual participei, realizado na Escola Municipal de Águas Claras (hoje renomeada Escola Municipal Celina Célia Gomes), situada no distrito de Águas Claras (Mariana-MG). 
As comunidades aí localizadas e atendidas pela escola são compostas preponderantemente de pessoas que se dedicam à agricultura familiar ou trabalham em fazendas da região que produzem carvão ou se dedicam à produção de leite que abastece laticínios da região. Este é um dos distritos de Mariana que possui algumas famílias cuja renda permite mandar seus filhos à sede do munícipio para dar continuidade aos estudos. A escola mantém turmas do o fundamental I e II, etapa da educação básica sob a responsabilidade do município, além de possuir algumas turmas do ensino médio, na verdade uma extensão da Escola Estadual Cônego Braga. Tal parceria mostrou-se importante, pois, ao contrário, muitos adolescentes não poderiam dar continuidade a seus estudos devido à dificuldade de deslocamento para o distrito de Monsenhor Horta, sede da escola estadual.

O projeto pedagógico foi elaborado de forma a integrar a feira cultural que é realizada anualmente e consiste em uma proposta formativa interdisciplinar que movimenta a comunidade escolar em torno de um tema previamente escolhido. Para o ano de 2011, foi elencado como tema norteador o estudo de diversos poetas. Na turma em que eu ministrava a disciplina História e a professora Juliana Cândido ${ }^{7}$, a quem agradeço a frutuosa parceria, era responsável pela de Português, os alunos escolheram como tema o poeta Carlos Drummond de Andrade. Privilegiamos então os poemas deste autor diretamente ligados à sua cidade natal, Itabira, e que são rememorados em placas distribuídas pela cidade.

Foi com gosto que, preparando-me para operacionalizar o projeto, retomei minhas leituras pessoais dos poemas de Carlos Drummond de Andrade, autor que pertence principalmente ao segundo movimento modernista, fase esta que é caracterizada pela presença de temas como regionalismos e críticas sociais. Desta forma, “o caráter ideológico influenciou [...] o período que se estende de 1924 a 1930

\footnotetext{
7 A professora Juliana Cândido foi uma parceria indispensável para que os aspectos organizacionais e pedagógicos do projeto pudessem ser realizados. Para isso foi necessário superar algumas barreiras burocráticas e financeiras que nos foram impostas á época. Ainda em relação a este relato de experiência, a mesma auxiliou-me de forma contundente, compartilhando suas memórias e alguns resultados dos trabalhos realizados por alunos.
} 
com dimensões variadas entre cada um dos artistas. [...] Por isso buscávamos um sentido com a nossa vanguarda - a afirmação da identidade nacional, a brasilidade" (BATISTA; BRITO, 2005, p. 312). Para José Guilherme Merquior, Drummond é uma das grandes "fundações" do Modernismo; segundo ele, "este poeta renovou a linguagem e o endereço de nossa lírica. Depois dele, uma e outra se abriram a modos mais objetivos de direção social, que já não cabem no subjetivismo anterior. $\mathrm{O}$ humanista dos primeiros livros deu ao lirismo uma agudeza reflexiva e irônica que o virou pelo avesso (MERQUIOR, apud ENCICLOPÉDIA Itaú Cultural, verbete Modernismo).

Revi, assim, a métrica livre de seus poemas (sem uso de rimas) e a não uniformidade dos versos (sem preocupação com a estética tradicional), além da linguagem mais objetiva, geralmente perpassada por uma fina ironia.

Em seguida, ainda no ambiente escolar, conduzimos, eu e a professora Juliana, um estudo das poesias e da conjuntura histórica à qual estavam ligados os poemas que se encontram expostos nas ruas de Itabira, como parte de um trajeto expositivo. Vencida a primeira etapa do projeto, passamos à segunda fase, que consistia justamente na visita a essa cidade, para poder perceber in loco o que foi estudado.

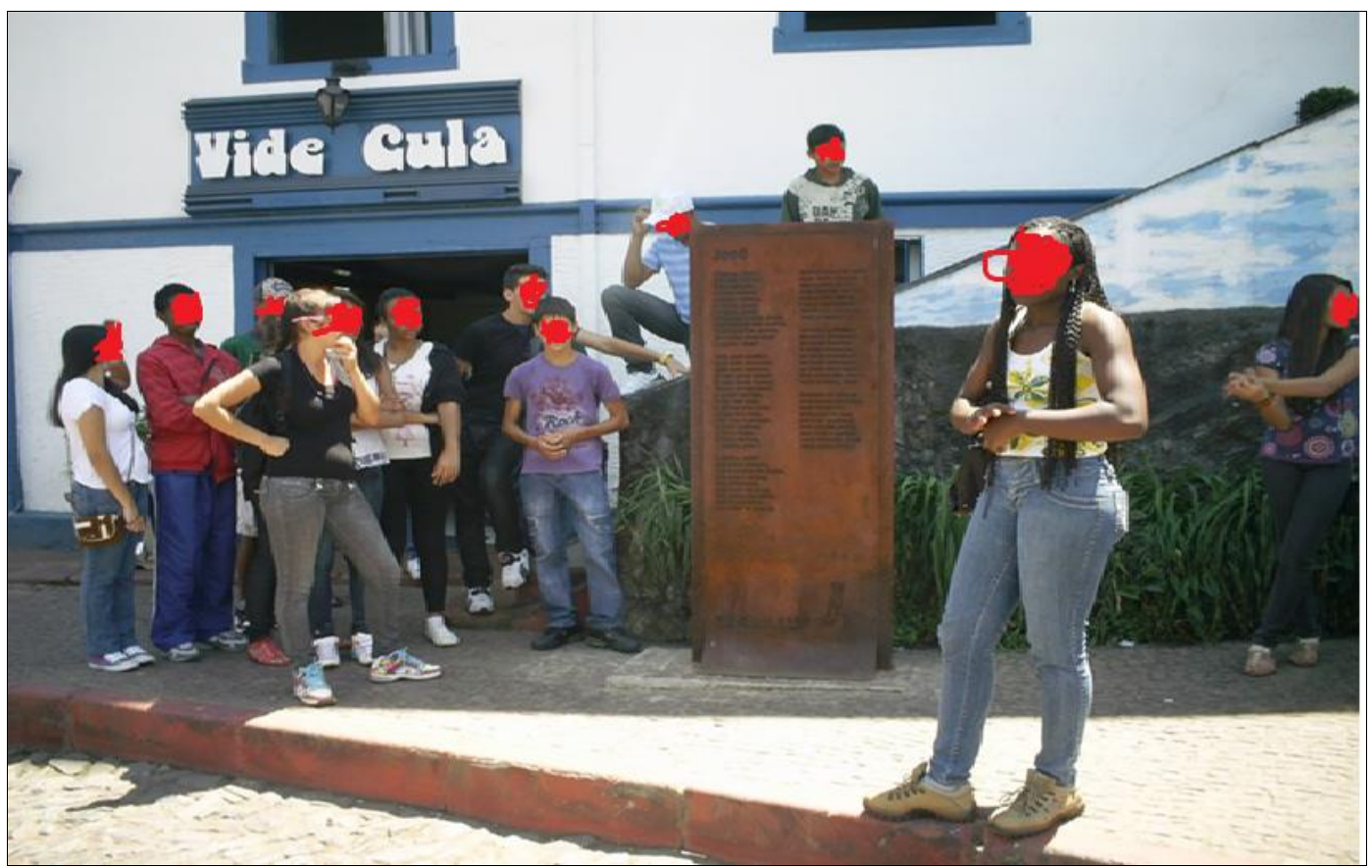

Fig. 1 - Visita dos estudantes da Escola Municipal Águas Claras à Itabira, 2011. Acervo pessoal 
Parte integrante e de grande importância, a visita a Itabira objetivava:

1- Ampliar de forma mais facilitada e prática o conhecimento da obra de Drummond, tornando esse saber mais significativo, de forma a enriquecer a percepção de características modernistas em seus poemas;

2- Incentivo à leitura das obras do referido poeta, através da percepção e emoção advindas do encantamento que a visita proporciona aos que têm a oportunidade de fazê-la.

3- Perceber as permanências e mudanças nos locais aos quais os poemas são ambientados.

4- Estabelecer a conexão entre a poesia e história para evidenciar que estas não são somente rima ou métricas perfeitas, mas que carregam em suas entranhas muito da época e local em que foram produzidas ou a um episódio ao qual se referem.

Para a disciplina de Língua Portuguesa/Literatura, o esperado após esta visita era a valorização por parte dos alunos da literatura, o gosto pela leitura e a percepção de traços modernistas na obra Drummondiana, além do entendimento por parte dos mesmos da importância de Carlos Drummond de Andrade para a literatura brasileira em conexão com a língua portuguesa. Em suma, essa parceria entre Literatura e História possibilitou destacar os aspectos histórico-sociais presentes na obra do autor ao evidenciar nesta as especificidades da cidade de Itabira e as particularidades da vida local e de seus moradores.

Contudo, a realização da segunda fase só ocorreu depois de transpormos vários obstáculos como o financiamento da viagem, que só foi possível depois que os professores se responsabilizaram pelo pagamento dos guias que nos acompanhariam na cidade de Itabira e os pais dos alunos ficarão responsáveis pelas despesas de alimentação de seus respectivos filhos.

Percorrer os "Caminhos Drummondianos" mostrou-se, efetivamente, uma descoberta de aprendizagem histórico-literária, que ia ocorrendo à medida que o 
trajeto descortinava-se aos nossos olhos. Ao vislumbramos os diferentes locais da cidade, conectando-os aos poemas que havíamos lido e também encontravam-se expostos em 44 pontos ou estações, estes adquiriam uma outra dimensão de compreensão.

[...] as poesias contam, respectivamente, a história dos pontos que possuem referências de personalidades, acontecimentos, homenagens, objetos ou celebrações. ${ }^{8}$ Ele é um presente para a sociedade local, regional, brasileira e mundial, uma vez que é aberta para todos, possibilita um incentivo à alfabetização, ao letramento por meio de poemas e dissemina a cultura de modo histórico e social. (LACERDA; SHITSUKA; MOREIRA, 2018, p. 10)

"Caminhos Drummondianos" é reconhecido como um projeto de Museu de Território em função de alguns critérios que o museólogo Mário de Souza Chagas articula no tripé patrimônio, comunidade e território:

[...] novos processos museológicos, com acentuado caráter social, estruturam-se a partir da inter-relação entre a comunidade, o patrimônio e o território. Desse tríptico são deduzidos os museus de comunidade, os museus de patrimônio (integral ou integrado) e os museus de território, conforme a ênfase em um dos três aspectos. No entanto, um museu de comum idade é também um museu que opera no território delineado pelas práticas comunitárias e com base em determinado patrimônio cultural (tangível e não tangível).

Da mesma forma, um museu de território só tem sentido se é trabalhado pela, com e para a comunidade, lançando mão de determinado conjunto de bens culturais. (apud LACERDA; SHITSUKA; MOREIRA, 2018, p. 15)

\footnotetext{
8 Os poemas contidos nestas placas são: A Ilusão do Migrante, O Maior Trem do Mundo, Banho, Lanterna Mágica, Documentário, Imagem Terra Memória, Coqueiro de Batistinha, Herói, Antônio Camilo de Oliveira, Procissão do Encontro, Terrores, Cultura Francesa, Sobrado do Barão de Alfié, José, paredão, O Inglês da Mina, Alfredo Duval, Primeiro Automóvel, Criação, Passeiam as Belas, Cemitério do Cruzeiro, Os Pobres, Sino, Furta-Fruto, O Criador, Casa, Câmara Municipal, O Dia Surge da Água, Canção de Itabira, Dodona Guerra, Os Gloriosos, Cemitério do Rosário, Pintura de Forro, Tantas Fábricas, Música Protegida, Guerra das Ruas, Memória Prévia, Repetição, Uma Casa, O Resto, Ausência, Confidência do Itabirano, Edifício Esplendor e Infância.
} 
Nos "Caminhos Drummondianos", a conexão poemas/lugares proporcionou uma maior compreensão da expressão literária e das inter-relações históricas dos mesmos, bem como propiciou sua ressignificação pelos discentes, em interface com suas próprias memórias pessoais sobre os lugares em que viviam. Ouvi-los sendo declamados pelo guia que conduzia o percurso, acrescidos de informações contextuais, levou toda equipe a "viajar no tempo" e "se sentir parte integrante das histórias", como relatou na ocasião a professora de Português da Escola de Águas Claras, Juliana Cândido. A professora destacou, no relato ${ }^{9}$ que promoveu aos colegas logo após a finalização do projeto, que a visita aos pontos históricos da cidade constituiu um momento ímpar em termos de inter-relação com os alunos e com a espacialidade sociocultural mineira, além de favorecer, sem dúvida, o entendimento e aumentar o interesse dos alunos pela obra do poeta. Todo o "clima" proporcionado ao se ouvir os poemas primorosamente declamados e sua conexão com a história ali vivida nos fez, alunos e professores, experimentar uma sensação de estarmos conectados aos acontecimentos narrados.

A constatação dos resultados além do esperado, como salientou a professora Juliana, ocorreu também através dos trabalhos entregues pelos alunos, que fizeram relatos significativos sobre suas impressões em relação à visita. Nessas narrativas, foi possível constatar que a ocasião proporcionou a oportunidade de articular literatura e história ao interligar poema-local nos diversos pontos visitados, tornando a visita culminância do projeto - um momento único e de proporções que não podem ser mensuradas. Esta conexão pode ser constatada no relato da aluna Carla ${ }^{10}$ do $3^{o}$ ano do ensino médio:

\footnotetext{
${ }^{9}$ Este relato foi rememorado pela Diretora da época em entrevista concedida à autora do artigo. Devido à exiguidade de registros escritos, foi necessário recorrer à colaboração desses colegas para reconstituir a proposta e execução do projeto e a análise dos resultados

${ }^{10} \mathrm{O}$ nome da aluna é hipotético, preservando-se sua identidade. Este relato faz parte de uma atividade avaliativa aplicada.
} 
Cibele Aparecida Viana

p. $521-543$
A Cidade como um Arquivo Aberto para o Ensino de História

Quando chegamos a estação 13, onde está localizado o casarão que hoje é o Hotel Itabira, cenário dos acontecimentos do poema José, me senti como se tivesse vivendo naquela época enquanto ouvia a história do poema e admirava o casarão. A história do rapaz apaixonado que pretendia raptar sua amada me tocou profundamente. No momento da aula quando estudamos os poemas, jamais imaginei que eles tinham sidos inspirados em acontecimentos reais e acho que se a história tivesse sido contada em sala de aula, não teria o mesmo encantamento.

Entre os 43 pontos visitados, trago como exemplo de como é enriquecedor essa experiência de visita guiada ao Museu de Território “Caminhos Drummondianos" o ponto 11, retratado na fotografia abaixo e que reproduz o poema denominado Terrores:

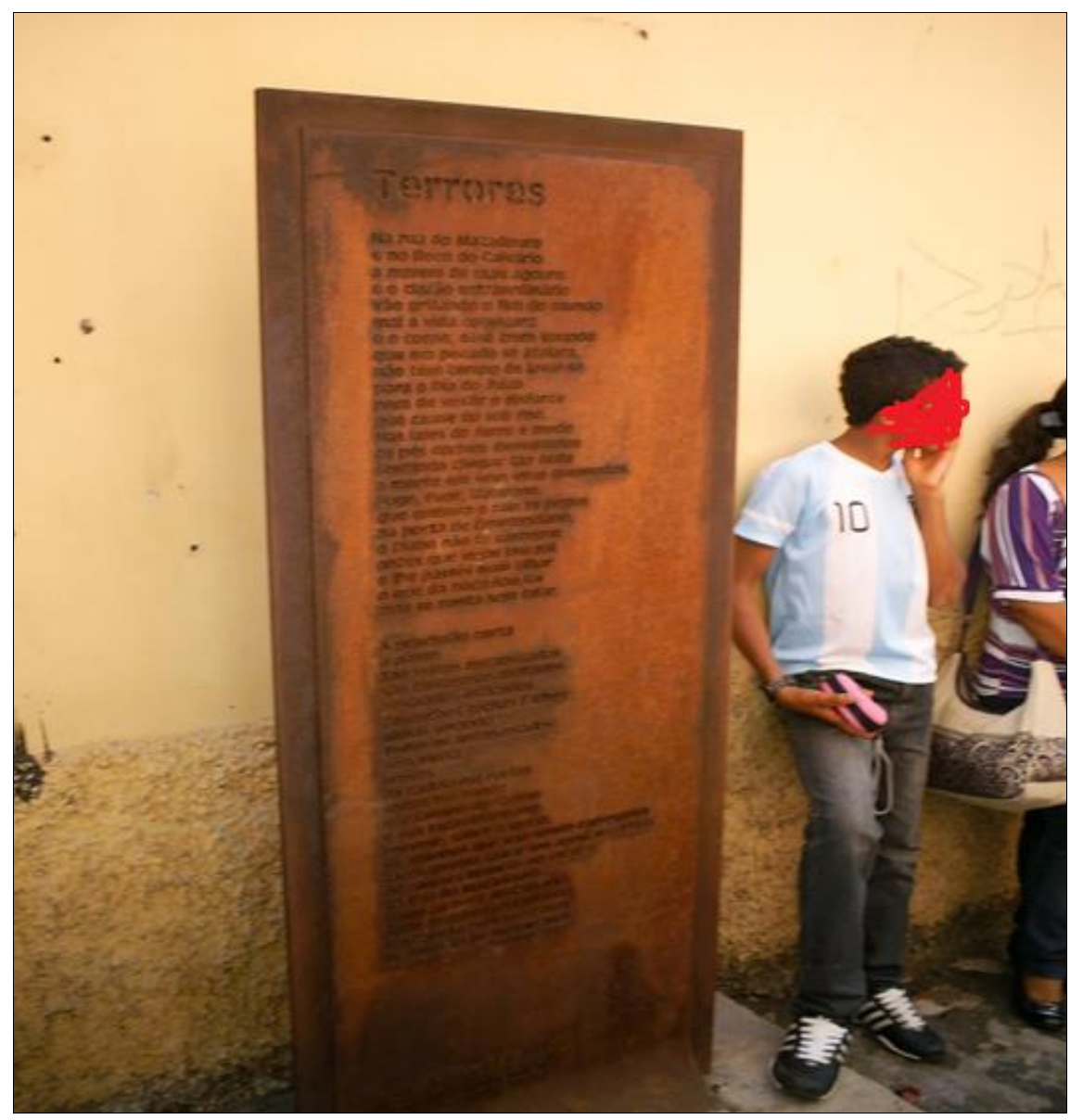

Fig. 2 - Visita dos estudantes da Escola Municipal de Águas Claras a Itabira, 2011. Acervo pessoal 


$$
\begin{gathered}
\text { Na Rua do Matadouro } \\
\text { e no Beco do Calvário } \\
\text { a nuvem de mau agouro } \\
\text { e o clarão extraordinário } \\
\text { vão gritando o fim do mundo } \\
\text { mal a vida começara } \\
\text { e o corpo, esse trem imundo } \\
\text { que em pecado se atolara, } \\
\text { não tem tempo de lavar-se } \\
\text { para o Dia do Juízo } \\
\text { nem de vestir o disfarce } \\
\text { Nas lajes de ferro e medo } \\
\text { os pés correm desvairados } \\
\text { sentindo chegar tão cedo } \\
\text { a morte em seus véus queimados } \\
\text { que cause dó sob riso. } \\
\text { Fuge, fuge, itabirano, } \\
\text { Que embora o raio te pegue } \\
\text { na porta de Emerenciano, } \\
\text { o Diabo não te carregue } \\
\text { antes que vejas teu pai } \\
\text { e lhe passes num olhar } \\
\text { o que da boca não sai }
\end{gathered}
$$

mas se conta sem falar. A procissão corta o passo.

São vultos encapuzados

são fantasmas alinhados

pesadelos esticados

fantoches tochas fachos

almas uivando

todos os antepassados

sem missa

presos da cadeia em ruínas

soltos em bando

o assassino do Carmo

e sua faca-relâmpago

enorme, sobre a igreja,

os anjinhos que vão sendo carregados

tão depressa que é um apostar corrida

de caixões brancos no escuro

da Rua do Matadouro

rumo ao Beco do Calvário

onde te espera o carrasco

e o Capeta com seu casco

de fogo ao pé do carrasco

(DRUMMOND, ano 2107, p.217,218) 
Este poema faz referência ao Beco do Calvário, que possui muitas histórias mencionadas pelos moradores mais antigos, segundo os quais o local foi palco de vários acontecimentos perpassados de sofrimento: ele servia de passagem para chegar à antiga cadeia do município, ${ }^{11}$ além de ser um atalho para se chegar ao cemitério antigo do Cruzeiro que ficava em frente à cadeia.

Segundo a história oral, o Beco do Calvário era o local onde os criminosos que vinham da Rua do Matadouro, antes de serem levados para a cadeia, eram torturados pela polícia. Também segundo Clovis Alvim, um psiquiatra itabirano, que escreveu muitas das histórias de Itabira, e no começo do século $X X$ as condições de higiene e medicação eram da época e morriam muitas crianças: eram tantas que, naquela época na Cidade, passava a ser um evento comum. Quando morria uma criança, para o enterro, reuniam-se as crianças vizinhas, colocava o "anjinho" no caixãozinho branco e saiam pela rua cantando: "Com minha Mãe estarei". O enterro da criança, e também as crianças que acompanhavam o enterro, para cortar caminho na ida do cemitério, passavam pelo Beco do Calvário. Conta-se também que na época de comemoração da Semana Santa, havia uma procissão só de homens, todos encapuzados e com uma tocha na mão, passavam a meia-noite neste beco batendo com cajado no chão. LACERDA; SHITSUKA; MOREIRA, 2018, p. 55)

Como dito acima, o Beco era o percurso para os diversos tipos de criminosos:

Também, naquela época, no distrito do Carmo, que fica distante cerca de $40 \mathrm{Km}$ em relação ao centro de Itabira, havia uma celebração de missa, um culto religioso católico, mensal, após a missa algumas pessoas seguiam para as vendas beber. A ingestão de bebidas alcoólicas sem moderação, muitas vezes tinha como consequência as provocações e brigas na qual se envolviam facas e instrumentos perfuro-cortantes. Os resultados desses acontecimentos eram: lesões, ferimentos e mortes. As armas brancas tipo faca, facão, canivete, estilete ou navalha eram as armas comuns dos moradores da época. Os assassinos também eram trazidos para Itabira. Eles passavam pelo Beco do Calvário para serem presos na cadeia que ficava em cima do morro. LACERDA; SHITSUKA; MOREIRA, 2018, p. 55)

\footnotetext{
${ }^{11}$ Esta detenção localizava-se no alto do morro, sendo desativada apenas em 2009.
} 
Os relatos ainda colocam o Beco como um local que incitava o imaginário infantil, além de servir de palco para os castigos dos escravos:

Outra história contada pelos antigos moradores de Itabira, é que existia na época um homem chamado Emerenciano, era de família nobre. Ele possuía o hábito de usar sempre uma capa preta e, por causa disso, as crianças pensavam que ele era um bruxo. Os pequeninos tinham medo da imagem que Emerenciano, caminhando pelo Beco do Calvário, lhes passava e muitos acreditavam que ele era bruxo. Outra lenda contada pelos antigos moradores de Itabira, existia no alto do beco um tronco onde os escravos eram amarrados e castigados publicamente, quando estes desobedeciam os seus senhores. (LACERDA; SHITSUKA; MOREIRA, 2018, p. 55)

Além desses pontos distribuídos pela cidade, o passeio ainda contempla a visita ao Memorial Carlos Drummond de Andrade e a casa onde viveu o poeta, que complementam esse mergulho pela obra e vida do autor ao entramos em contato com o acervo sobre a vida de Drummond, doados pela Fundação Cultural do Banco do Brasil, pela biblioteca da Fundação Cultural Carlos Drummond de Andrade, familiares e amigos. No local, temos acesso a variados objetos, tais como uma coleção de cartas, recebidas de grandes autores e familiares; missivas que ele trocava com os amigos da pequena cidade; os poemas que não foram publicados; o recadinho da mãe, que de tão valioso ficou guardado até amarelar... Há também recortes das crônicas que o poeta escreveu para o Jornal O Cometa, que foram emolduradas na parede.

Para Pierre Nora (1997, p 18) “os lugares de memória não são aqueles dos quais nos lembramos, mas lá onde a memória trabalha". Percorrer as ruas de Itabira lendo os poemas de Drummond efetivamente mobilizou, evocou antigas memórias, produziu novos sentidos, que iriam transformar-se, eles também, em memórias, agora traduzidas em artigo. 


\section{3- História e Memória}

Foi proposta neste texto uma reflexão acerca do cruzamento entre História e Memória, através da literatura e da cidade, entendidas como "arquivos abertos", que se superpõem e trocam significados. O urbano, assim, pode ser utilizado como um arcabouço que possibilita ao docente favorecer aos alunos diversas possibilidades de conectar passado e presente. A cidade é um local que proporciona um variado leque de possibilidades de reelaboração desse passado, ela se apresenta como uma "teia" permeada de diversas memórias:

Para Ricoeur, as memórias individual e dos objetos se entrelaçam. Ademais, a memória das 'coisas' e memória de mim mesmo coincidem: aí, encontro também a mim mesmo, lembro-me de mim, do que fiz, quando e onde o fiz e da impressão que tive ao fazê-lo'.$^{12}$ Com isso, podemos dizer que a memória pessoal se expressa no coletivo, e o contato dos indivíduos com essas memórias na cidade proporciona relações de poder, resistência, esquecimento ou enaltecimento de um passado que viveu, ou que gostaria de ter vivido (ALMEIDA, 2011, p. 29).

Nesta tarefa de ensinar através do que está omitido, do que é mantido mudo por trás dos edifícios, das ruas e das esquinas, o professor de História se defronta com um desafio, que deve vencer: desvendar a cidade que se apresenta como um palimpsesto, como um enigma a ser decifrado.

Esta definição primeira do palimpsesto nos fornece uma chave para os olhos do historiador, quando se volta para o passado. Há uma escrita que se oculta sobre outra, mas que deixa traços; há um tempo que se escoou, mas que deixou vestígios que podem ser recuperados. Há uma superposição de camadas de experiência de vida que incitam ao trabalho de um desfolhamento, de uma espécie de arqueologia do olhar, para a obtenção daquilo que se encontra oculto, mas que

${ }^{12}$ A autora reporta-se ao seguinte texto: RICOEUR, Paul. A memória, a história, o esquecimento. Campinas, SP: Editora da Unicamp, 2007, p. 110. 
deixou pegadas, talvez imperceptíveis, que é preciso descobrir (PESAVENTO, 2014, p. 27).

Ao percorrer os "Caminhos Drummondianos", foi possível resgatar com os alunos uma cidade e suas histórias por trás dos poemas e lugares aos quais eles se referem. Cada esquina nos leva a um mundo onde o hoje e o ontem se sobrepõem através das inspirações contidas nos poemas e ligados a eles por cada ponto aos quais se referem e que traduzem muito da potencialidade de experiências e sensibilidades envolvendo Itabira e os itabiranos.

A cidade, ao ser analisada e problematizada como um palimpsesto de diferentes tempos - que coexistem e não se sobrepõem - apresenta uma grande potencialidade educativa para a constituição dessas competências nos sujeitos aprendizes. [...] A experiência com a mudança temporal, quando não expressa em toda a extensão urbana, ou nos trajetos percorridos no dia a dia, se exprime na constituição de lugares, e de vínculos com esses lugares. (ALMEIDA, 2011, p. 31)

A proposta de se alargar a concepção da cidade para além de um patrimônio histórico, que é importante conservar, mas que deve ser abordado para além de sua beleza arquitetônica, de seus bens matérias, imateriais ou paisagens pitorescas, vai de encontro à possibilidade do indivíduo:

[...] de entrecruzar seus diferentes saberes e de pertencer ativamente à cidade. Que não apenas conservassem seus patrimônios históricos alargando seus significados, e apropriando-se, também, de sua dimensão cultural mais ampla -, mas que se mostrassem hábeis para recriá-los, a partir de questões mobilizadoras situadas no presente, tais como a construção da cidadania participativa, da solidariedade social, de um 'novo' nível de consciência coletiva, em torno de algo em comum (sua cidade). (GALZERANI, 2010, p. 611-612).

Quero pontuar que o relato aqui descrito sobre o trabalho desenvolvido em âmbito de uma feira cultural em 2011 só foi possível com a colaboração de algumas pessoas que atuaram no projeto e possuíam pouquíssimos (mas valiosos) registros a 
seu respeito. O leitor, talvez sinta falta de depoimentos mais extensos por parte dos alunos, professores e comunidade escolar, os quais não foram devidamente arquivados e se perderam.

Fica aqui o alerta aos professores para registrarem e arquivarem o material produzido e o feedback dos estudantes e dos docentes quanto aos projetos e práticas desenvolvidas no ensino escolar. Tais materiais são fontes de grande importância para a construção do conhecimento com seus alunos e podem contribuir enormemente como uma constatação de que o Ensino, e neste caso especificamente o de História, é perpassado por iniciativas que procuram diversificar e proporcionar aos seus alunos experiências que tornam a aprendizagem mais prazerosa e significativa. Ademais, tais registros são uma preciosa contribuição para a formulação da reflexão acadêmica sobre a especificidade, a complexidade e a validade do Ensino de História na esfera escolar.

\section{Referências bibliográficas:}

ABUD, Katia Maria. A construção de uma Didática da História: algumas ideias sobre a utilização de filmes no ensino. História. São Paulo, v. 22, n. 1, p. 183-193, 2003.

ALMEIDA Rita de Cássia Mesquita de. Palimpsestos Urbanos: aprendizagens históricas em tramas de memórias da cidade. 2011. 134f. Dissertação (Mestrado em Educação). Universidade Federal de Juiz de Fora, Juiz de Fora, 2011.

Andrade, Carlos Drummond de. 1902-1987. Boitempo: Menino antigo. Carlos Drummond de. Andrade; posfácio John Gledson - 1aㅡ ed.- São Paulo: Companhia das Letras, 2017.

AQUINO, Maurício. Memória e Temporalidade no Ensino de História: questões conceituais e possibilidades metodológicas. VII Congresso Internacional de História. Disponível em: http://www.cih.uem.br/anais/2015/trabalhos/1380.pdf. Acesso em 29/07/2020

BRASIL - MEC. Parâmetros Curriculares Nacionais: História. 1998. Disponível em: http://portal.mec.gov.br/seb/arquivos/pdf/pcn 5a8 historia.pdf - acesso em: 26/06/2020, p.84 
CHOPIN, A. História dos livros e das edições didáticas: sobre o estado da arte. In: Educação e Pesquisa. São Paulo, v.30, n,3, set./dez.2004, p.549-566

BATISTA, Marta Rossetti; BRITO, Ronaldo. Modernismo. In: Mestres do Modernismo. São Paulo. Imprensa Oficial, 2005.

GALZERANI, Maria Carolina Bovério. A cidade como espaço de aprendizagem da história: em foco um projeto de educação patrimonial. In: SANTOS, Lucíola Licínio de Castro Paixão (org.). Convergências e tensões no campo da formação e do trabalho docente. Belo Horizonte: Autêntica, 2010.

HALBWACHS, Maurice. A memória coletiva. São Paulo: Centauro, 2004, p.73.

LE GOFF. Jacques. História e memória. Tradução Bernardo Leitão... [et al.]. - 5ª ed. Campinas, SP: Editora da UNICAMP, 2003.

LARCEDA, Dadá Lage; SHITSUKA, Ricardo, MOREIRA, Dorlivete. Caminhos Drummondianos. Belo Horizonte: Poisson, 2018.

LE GOFF, Jacques. História e Memória. Campinas, SP: Editora da Unicamp, 2003.

LEMME, Paschoal. O Manifesto dos Pioneiros da Educação Nova e suas repercussões na realidade educacional brasileira. Revista Brasileira de Estudos Pedagógicos. Brasília, v. 86, n. 212, 2005.

MODERNISMO (Segunda Geração). In: ENCICLOPÉDIA Itaú Cultural de Arte e Cultura Brasileiras. São Paulo: Itaú Cultural, 2020. Disponível em: http://enciclopedia.itaucultural.org.br/termo12178/modernismo-segunda-geracao. Acesso em: 20 out. 2020. Verbete da Enciclopédia.

NORA, Pierre. Entre Memória e História: A problemática dos lugares Tradução de Yara Aun Khoury. Projeto História: Revista do Programa de Estudos PósGraduados de História. São Paulo, v.10, p,7-28, 1993, dez 1993.

PESAVENTO, Sandra Jatahy. Com os olhos no passado: a cidade como palimpsesto. Esboços. v. 11, p. 25-30, 2004.

Cidades visíveis, cidades sensíveis, cidades imaginárias. Revista Brasileira de História. São Paulo, vol. 27, no 53, jan.-jun., p. 11-23, 2007.

Muito além do espaço: por uma história cultural do urbano. Estudos Históricos. Rio de Janeiro, v. 8, n. 16, p. 279-290, 1995. 
POLLACK, Michael. Memória e identidade social. Estudos Históricos. Rio de Janeiro, v. 5, n. 10, p. 200-212, 1992.

ROLNIK, Raquel. O que é cidade. São Paulo: Brasiliense, 1995.

SANTOS, Silvana Maria Pantoja dos. Literatura e memória entre os labirintos da cidade: representações na poética de Ferreira Gullar e H. Dobal. 2013.182f. Tese (Doutorado em Letras). Universidade Federal de Pernambuco, Recife,2013.

SPINA, Gabriel Luís; SERRATO, Edgar Bruno Franke. Patrimônio histórico e cultural: uma revisão bibliográfica. Educação. Batatais, v. 5, n. 3, p. 99-116, 2015. 